\section{Proximal humeral fracture surgery in the COVID-19 pandemic: advocacy for regional anesthesia}

\section{To the Editor}

On 23 April 2020, the National Health Institute reported $177 \quad 143$ confirmed cases and more than 23188 confirmed COVID-19 deaths affecting Italy. Approximately 19628 health workers became infected during the execution of their duties, and among them, 69 clinicians died. ${ }^{1}$

The odds of transmission of acute respiratory infection to a healthcare professional is known to be 6.6 times when exposed to tracheal intubation. ${ }^{2}$

Hence, regional anesthesia (RA) as sole technique may be preferred for providing anesthesia care wherever possible in trauma patients with suspected COVID-19 infection. Besides decreasing the need for airway manipulation, RA may lower the risk of postoperative complications and reduces the length of stay in the overloaded post anesthesia care unit (PACU) and critical care units. $^{3}$

Proximal humeral fracture (PHF) is a frequent occurrence in elderly patients, accounting for about $10 \%$ of all fractures in this age group. ${ }^{4}$ PHF requires emergent surgery regardless of their non-fasted state or health status and presents a unique challenge to anesthesia providers as no single brachial plexus block will likely be adequate for surgical anesthesia. Although the interscalene (IS) block is the preferred technique for surgeries involving the shoulder and the upper arm, this block commonly misses the C8-T1 roots (lower trunk), resulting in dermatomal sparing of parts of the arm. A supraclavicular (SC) block can provide entire upper extremity anesthesia distal to the shoulder but will likely miss the axillary nerve, which is a key component of shoulder innervation.

Following the COVID-19 outbreak in the north of Italy, we now routinely combine ultrasound-guided IS and separate SC block (IS-SC block) (whenever possible) to allow
PHF surgery to be performed entirely under RA (with patient approval) in positive, or suspected to be positive, patients. We typically use $30 \mathrm{~mL}$ of a $1: 1 \mathrm{mix}$ of $2 \%$ mepivacaine and $0.5 \%$ levobupivacaine to complete both blocks. Our experience in 12 patients who underwent open reduction and internal fixation or shoulder arthroplasty (hemi- or reverse) suggests that surgical anesthesia can be achieved, and optional light sedation (midazolam 0.01$0.03 \mathrm{mg} / \mathrm{kg}$ and $/$ or fentanyl $0.25-1.0 \mu \mathrm{g} /$ $\mathrm{kg}$ ) is administered at the discretion of the attending anesthesiologist.

We believe an IS-SC block can represent a valid alternative to general anesthesia in the management of anesthesia and analgesia for upper limb surgery involving C5-T1 dermatomes. This becomes particularly important for fragile patients in the context of ongoing respiratory infection and for the healthcare team, which is less exposed to risk of transmission of COVID-19, especially in case of shortages or rationing of personal protective equipment.

Andrea Tognù $\odot,{ }^{1}$ Enrico Barbara, ${ }^{2}$ Ilaria Pacini, ${ }^{3}$ Mario Bosco ${ }^{4}$

${ }^{1}$ Anesthesia, Intensive Care and Pain Therapy, Istituto Ortopedico Rizzoli Istituto di Ricovero e Cura a Carattere Scientifico, Bologna, Italy

${ }^{2}$ Anesthesia, Intensive Care and Pain Therapy, Humanitas Mater Domini Hospital, Castellanza, Italy ${ }^{3}$ Department of Obstetrics and Gynecology, Sant' Orsola Malpighi University Hospital, Bologna, Italy ${ }^{4}$ Anesthesia and Intensive Care Unit and Pain Therapy, Santo Spirito e Nuovo Regina Margherita Hospital, Roma, Italy

Correspondence to Dr Andrea Tognù, Istituto Ortopedico Rizzoli Istituto di Ricovero e Cura a Carattere Scientifico, Bologna 40136, Italy; up4run@gmail.com

Contributors AT, EB: writing of the article; planning conducting and reporting the work. IP, MB: scientific support.

Funding The authors have not declared a specific grant for this research from any funding agency in the public, commercial or not-for-profit sectors.

Competing interests None declared.

Patient consent for publication Not required.

Provenance and peer review Not commissioned; internally peer reviewed.

This article is made freely available for use in accordance with BMJ's website terms and conditions for the duration of the covid-19 pandemic or until otherwise determined by BMJ. You may use, download and print the article for any lawful, non-commercial purpose (including text and data mining) provided that all copyright notices and trade marks are retained.

(C) American Society of Regional Anesthesia \& Pain Medicine 2021. No commercial re-use. See rights and permissions. Published by BMJ.

Check for updates

To cite Tognù A, Barbara E, Pacini I, et al. Reg Anesth Pain Med 2021;46:375-376. 
PostScript

Received 24 April 2020

Revised 30 April 2020

Accepted 30 April 2020

Published Online First 13 May 2020

\section{Linked}

- http://dx.doi.org/10.1136/rapm-2020-101729

- http://dx.doi.org/10.1136/rapm-2020-101733

Reg Anesth Pain Med 2021;46:375-376.

doi:10.1136/rapm-2020-101626

ORCID ID

Andrea Tognù http://orcid.org/0000-0002-8840-4872

\section{REFERENCES}

1 Epidemia COVID-19. Available: www.epicentro.iss.it/ coronavirus/bollettino/Bollettino-sorveglianza-integrataCOVID-19_23-aprile-2020.pdf

2 Tran K, Cimon K, Severn M, et al. Aerosol generating procedures and risk of transmission of acute respiratory infections to healthcare workers: a systematic review. PLOS One 2012;7:e35797.

3 Warren J, Sundaram K, Anis H, et al. Spinal anesthesia is associated with decreased complications after total knee and hip arthroplasty. J Am Acad Orthop Surg 2020;28:e213-21.

4 Lanting B, MacDermid J, Drosdowech D, et al. Proximal humeral fractures: a systematic review of treatment modalities. J Shoulder Elbow Surg 2008;17:42-54. 